\title{
New insights in twin screw expander performance for small scale ORC systems from 3D CFD Analysis
}

\author{
Iva Papes ${ }^{1}$, Joris Degroote, Jan Vierendeels \\ Department of Flow, Heat and Combustion Mechanics, Ghent University, Belgium
}

\begin{abstract}
Twin screw expanders are widely used for power generation in small scale Organic Rankine Cycles (ORC). In order to increase the efficiency and maximize the generated power, an optimized design and appropriate operating conditions should be used. The use of Computational Fluid Dynamics (CFD) allows the analysis of the flow inside these machines which is impossible to investigate experimentally but which is influencing the performance of the expander. Some of the challenges when performing CFD analysis in these machines are the complexity of the rotors' motion and the properties of the refrigerant. In this paper a 3D CFD analysis of a twin screw expander is presented. The 3D blockstructured grid for the twin screw expander is constructed from the solution of Laplace problems in two-dimensional sections on an unstructured grid of the same geometry. During the transient calculations, grid nodes are moved while keeping the mesh topology. The properties of the refrigerant R245fa have been evaluated using the ideal gas Equation of State (EoS), the Aungier Redlich-Kwong EoS and the CoolProp. 3D CFD analysis of the screw expander showed that the difference in power output between the ideal gas EoS and the Aungier Redlich-Kwong EoS is $8 \%$ and between Aungier Redlich-Kwong EoS and CoolProp is negligible for operating conditions of interest. To investigate the performance of the expander, different pressure ratios and rotational speeds were studied for two different designs of the twin screw expander. The flow analysis inside the clearances that are forming leakage paths gives more insight in the performance of the expander. It is concluded that the biggest pressure drop is caused by a throttling loss at the inlet port and therefore an optimized design of the inlet port is necessary.
\end{abstract}

Keywords: Computational Fluid Dynamics, Twin Screw Expander, R245fa, Aungier Redlich-Kwong EoS, Organic Rankine Cycle

\section{Nomenclature}

\section{Symbols}

$\dot{m} \quad$ Mass flow rate through the inlet port $(\mathrm{kg} / \mathrm{s})$

$\dot{W} \quad$ Work rate $(\mathrm{W})$

$\phi \quad$ Filling factor (-)

$\pi \quad$ Pressure ratio (-)

$c_{p} \quad$ Specific heat $(\mathrm{J} / \mathrm{kg}-\mathrm{K})$

$D \quad$ Diameter of the rotors (m)

$k \quad$ Specific heat ratio (-)
${ }_{10} \quad L \quad$ Length of the rotors (m)

$n \quad$ Rotational speed, male (rot $/ s$ )

$P \quad$ Pressure $(\mathrm{Pa})$

$R \quad$ Real gas constant $(\mathrm{J} / \mathrm{kg} / \mathrm{K})$

$T \quad$ Temperature (K)

$v \quad$ Specific volume of the working fluid calculated from the temperature and pressure $\left(\mathrm{m}^{3} \mathrm{~kg}^{-1}\right)$

$V_{\text {fill }} \quad$ Volume at the end of filling $\left(\mathrm{m}^{3}\right)$

\footnotetext{
${ }^{1}$ Corresponding author.Tel:+32(0)92643300.

E-mail address:iva.papes@ugent.be
} 


\begin{tabular}{|c|c|}
\hline$V_{\text {ports }}$ & $\begin{array}{l}\text { Growth of the chamber vol } \\
\text { nection with additional por }\end{array}$ \\
\hline$z$ & Number of teeth, male (-) \\
\hline \multicolumn{2}{|c|}{ Subscripts } \\
\hline$c$ & critical \\
\hline \multicolumn{2}{|c|}{ calc, fill calculated at the filling } \\
\hline \multicolumn{2}{|c|}{ calc, ports calculated at the ports } \\
\hline dis & discharge \\
\hline $\exp$ & expander \\
\hline fill & filling \\
\hline
\end{tabular}
is isentropic
$m r \quad$ male rotor

30 Abbreviations

$\begin{array}{cl}\text { ARK } & \text { Aungier Redlich-Kwong } \\ \text { CFD } & \text { Computational Fluid Dynamics } \\ \text { EOS } & \text { Equation of State } \\ \text { ORC } & \text { Organic Rankine Cycle } \\ { }_{35} \text { TFC } & \text { Trilateral Flash Cycle } \\ \text { UDF } & \text { User defined function }\end{array}$

\section{Introduction}

With more strict energy and pollution constraints, low grade waste heat presents an attractive opportunity for an emission free and less costly energy resource. In the present technologies for low grade waste heat recovery, such 40 as the ORC, the energy conversion machines are still not enough investigated. The performance of screw expanders, which are highly suitable for ORC systems [1, 2], should be optimized by choosing the right screw expander geometry and operating conditions.

First attempts of using the twin screw expander in the geothermal community date back to the late seventies and early eighties. In the past and even at this moment, screw expanders are designed as screw compressors with opposite 45 sense of rotation. In the beginning of their commercial use, screw machines were mostly developed by Lysholm. In 1982, an analytical model of a helical screw expander has been derived by Margolis [3]. Taniguchi et al. [4] proposed the use of two-phase screw expanders with organic fluids instead of water in a similar system to that proposed by Eliot [5]. In 1993 and 1996 Smith et al. [6, 7] proposed a Trilateral Flash Cycle (TFC) with a Lysholm machine used as a two-phase expander. They proposed a TFC system as a doable alternative to an ORC system in geothermal

50 applications. In 2005, Smith et al. [8] presented the significant potential of screw expanders in making geothermal power more efficient and cost effective, especially for small power outputs up to 3MW and brine temperatures from $100^{\circ}$ to $140^{\circ}$. In these conditions, screw expanders used in ORC systems show their superiority over the expanders used in TFC systems which are not suitable in all conditions (especially not for lower condensing temperatures). It was concluded that in screw expanders for ORC systems, both cost and efficiency should be improved. More 55 recently, the numerical and experimental study on the performance of oil-free and oil-injected screw expanders in waste heat recovery applications was carried out by Wang et al. [9]. This mathematical model included the equations of conservation of mass and energy applied to an instantaneous control volume within the expander with different leakage paths for oil and gas.

Despite the comprehensive experience gained in the field of screw machines the design of such a machine still 60 represents a challenge [10]. The capability to analyse the performance of such complex screw machines is very often limited by the thermodynamic models which describe the behaviour of the fluid or the inability to get proper experimental data. With CFD these limits can be overcome. Analysis of the flow within the screw expander by means of CFD calculations can be beneficial in the design optimization which leads to better efficiency. To take the rotation of the screws into account in the transient calculations, the grid for the CFD calculations should move for 65 every angular position.

Clearances inside screw expanders are in order of tens of microns which is very small compared to the overall size of the expander. Still, good grid resolution and alignment of the grid with the dominant flow direction should be obtained in these areas in order to calculate leakage flows correctly. Therefore, a block-structured grid generator should be used.

70 Until now, only two block-structured grid generators have been presented that are able to perform calculations for a screw machine. The pioneer work in the grid generation for screw machines was presented in 1999 by Kovacevic 

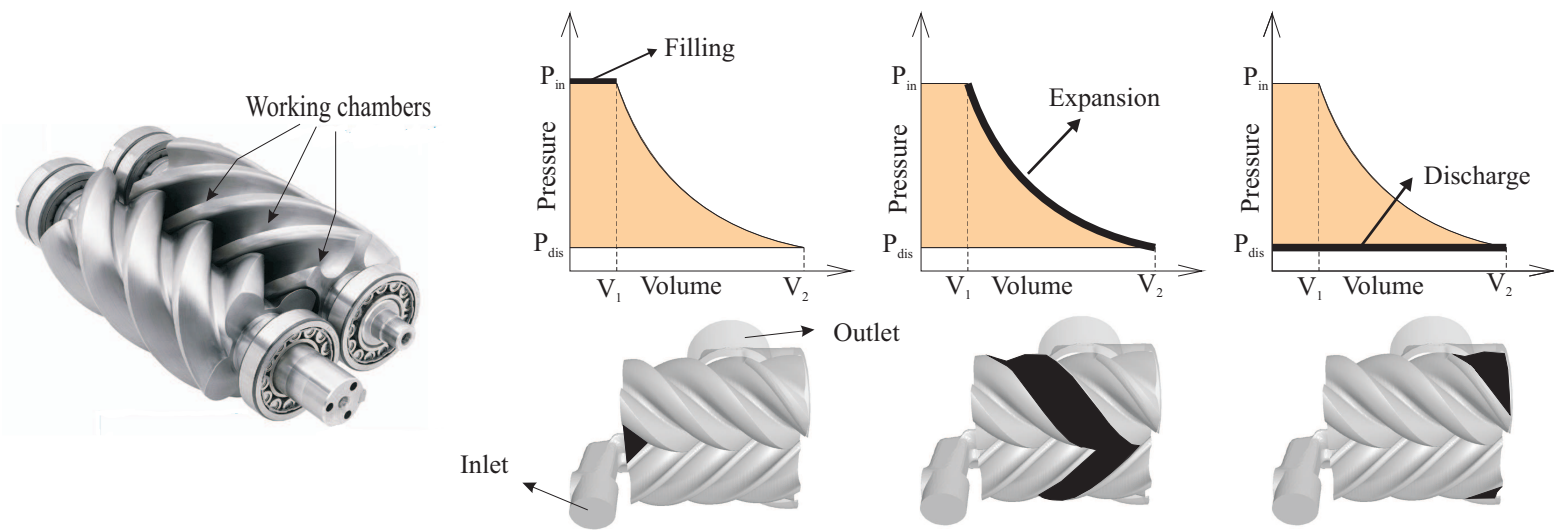

Figure 1: Working principle of a twin screw expander

et al. [11]. In that work the analytical rack generation method was used to generate a block-structured grid. This method was recently used in CFD calculations of an air screw expander [12]. This was also the first attempt to use 3D CFD calculations for the analysis of screw expanders. Another approach to grid generation for screw machines was presented by one of the authors in 2004 [13]. The algorithm used the so-called differential method [14] which is more suitable for complex geometries as in screw machines. They developed high-quality block-structured grids starting from the solution of the Laplace problem obtained on an unstructured grid of the same geometry. CFD calculations of a twin screw compressor using this grid showed good agreement with experiments [15]. Consequently, in this paper the authors used the same approach to perform the CFD calculations of a twin screw expander.

The motivation of this research was to study the flow inside a screw expander which will help in optimisation of the screw expander's performance. Special focus is on modelling real gas effects for refrigerant R245fa and its implementation since an ideal gas EoS shows big deviations for the working conditions of interest [16]. The flow analysis inside the clearances presented in this paper gives a better overview of the leakage losses which affect the volumetric efficiency.

\section{Geometry definition}

A twin screw expander is a positive displacement machine consisting of a pair of screw rotors inside the casing, which are forming working chambers. The ideal expansion process for a screw expander shown in Fig. 1 consists of an isobaric filling up to $V_{1}$, isentropic expansion up to the discharge pressure and an isobaric discharge which starts at the moment the volume reaches its maximum $V_{2}$. However, in the real expansion process several losses occur which affect the performance of the expander.

The screw expander used for this study has a 4/6 lobe (male/female) arrangement with a nominal operating speed of $6000 \mathrm{rpm}$. The male and female rotor diameters are approximately $70 \mathrm{~mm}$. The L/D ratio is 1.9 with a wrap angle of $302^{\circ}$ on the male rotor.

In this paper, two expander designs are studied. The first design has two additional inlet ports, besides the normal inlet. Such a design with additional ports (Fig. 2) was presented as a patent for a two-phase vapour expander in [17]. In that patent a small percentage of a compatible natural or synthetic lubricating oil (between $0.5-2 \%$ by weight) is mixed with the working fluid and the mixture is supplied through the inlet port and two additional ports. The second design is without additional inlet ports with the working fluid entering only through the inlet port. The performance analysis is done for both designs (both oil-free) in order to indicate the main differences in the flow and performance of the screw expander.

The volume curve of the working chamber depends only on the angle of rotation as shown in Fig. 3 The formation of a chamber starts at $\theta=0^{\circ}$ (Fig. 3). When $\theta=7^{\circ}$, the chamber is in connection with the inlet port. As the rotors turn, the volume of the chamber is rising together with the increase in the inlet surface area, and the chamber is filled with the working fluid. When the inlet area starts to decrease, the volume of the chamber is still increasing. This 


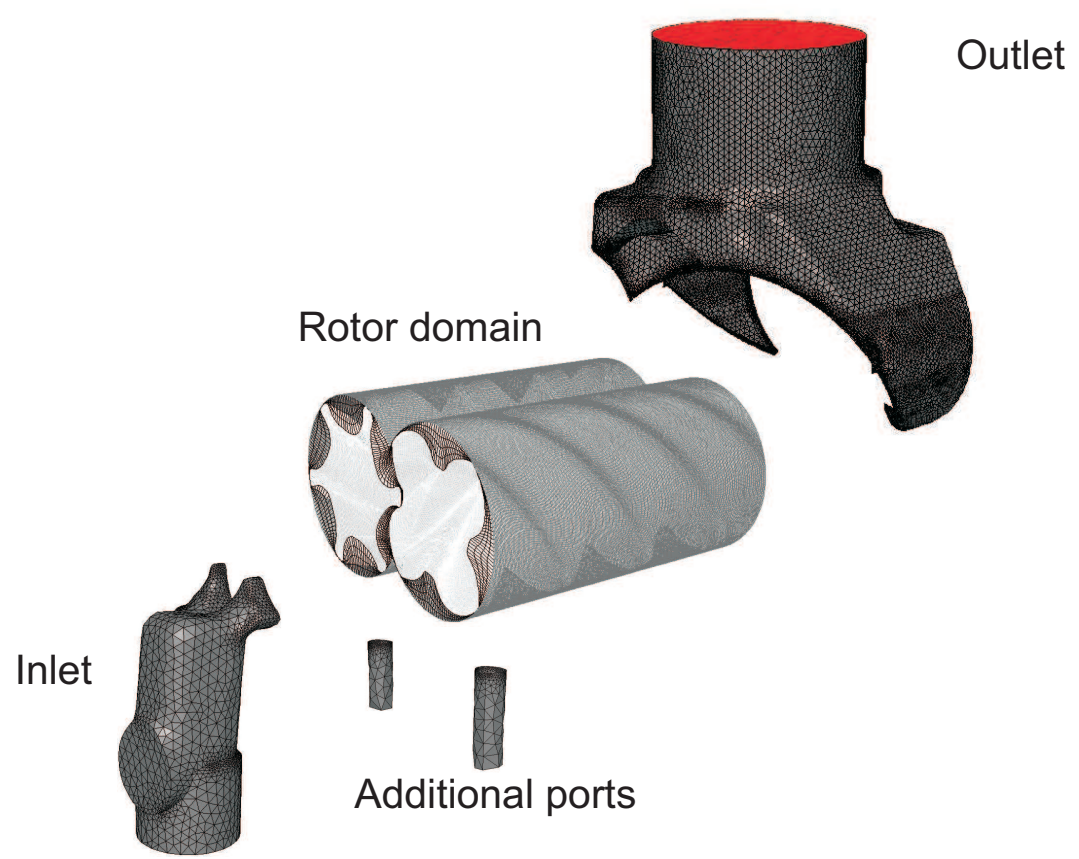

Figure 2: 3D mesh of the twin screw expander

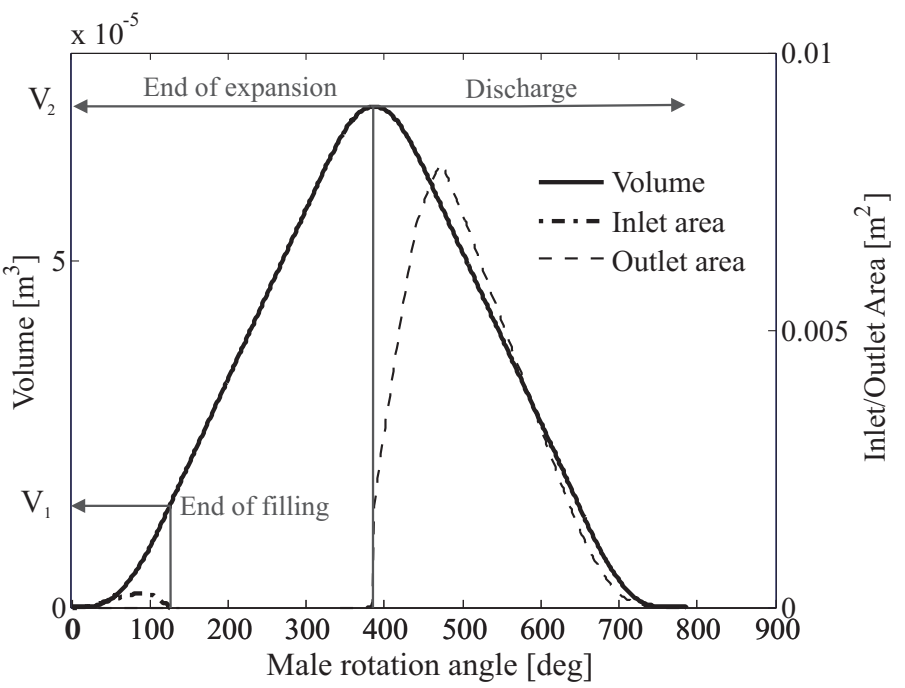

Figure 3: Volume curve with inlet and outlet surface areas as a function of the male rotation angle

causes the pre-expansion of the working fluid. The filling ends at $\theta=126^{\circ}$ after which the working fluid expands with increasing volume of the chamber. Once the maximum volume $V_{2}$ is achieved $\left(\theta=387^{\circ}\right)$, the connection with the outlet is established and the volume starts to reduce. The discharge will continue until the volume disappears.

The built-in volume ratio is one of the essential parameters of screw machines and can be defined as the ratio of the discharge volume $V_{2}$ to the inlet closure volume $V_{1}$. If the internal built-in volume ratio is too high for a given set of operating conditions, the fluid remains trapped longer than necessary, leading to a pressure drop below the discharge pressure (over-expansion). On the contrary, if the internal volume ratio is too low, the fluid in the chamber remains above the discharge pressure when the discharge/outlet port starts to open (under-expansion). Both, over- and underexpansion will affect the performance of the expander. 


\section{Grid generation}

The geometry of the twin screw expander is decomposed into four parts as shown in Fig. 2 A moving block structured grid is used within the rotor domain and stationary, unstructured triangular grids are used for the inlet, outlet and additional ports as they are not moving during the rotation of the screws of the expander. The number of cells in each part is shown in Table 1 with the total number of 2060515 cells.

\begin{tabular}{|l||c|c|c|c|}
\hline & Rotors & Inlet & Outlet & Ports \\
\hline Num of cells & 570000 & 51789 & 1420688 & 18038 \\
\hline
\end{tabular}

Table 1: Number of cells in the different parts of the expander domain

In the deforming rotor domain, the grid generation tool is used as described in [15]. The grid is built by stacking two-dimensional block-structured grids (Fig. 4) in axial slices of the casing. The grid nodes are mainly moving in the radial direction and only to a limited amount in the tangential direction to accommodate stretching of the mesh towards the gap between the rotor tip and the casing. As a result, the nodes of the cells are moving inside the rotor domain with the cell definition unchanged (ALE, Arbitrary Langrangian-Eulerian method).

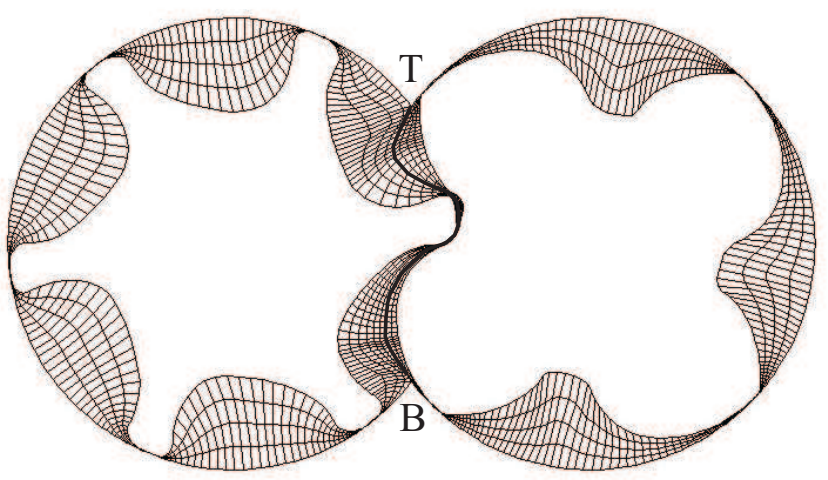

Figure 4: Two-dimensional grid slice of the twin screw expander

To generate the grid in the two-dimensional slices, the solution of the Laplace equation $\nabla^{2} \phi=0$ is used on a triangular unstructured grid in the two-dimensional axial slices. This triangular grid is only used to obtain the potential solution. Gridlines of the block-structured grid are then constructed mainly parallel and perpendicular to

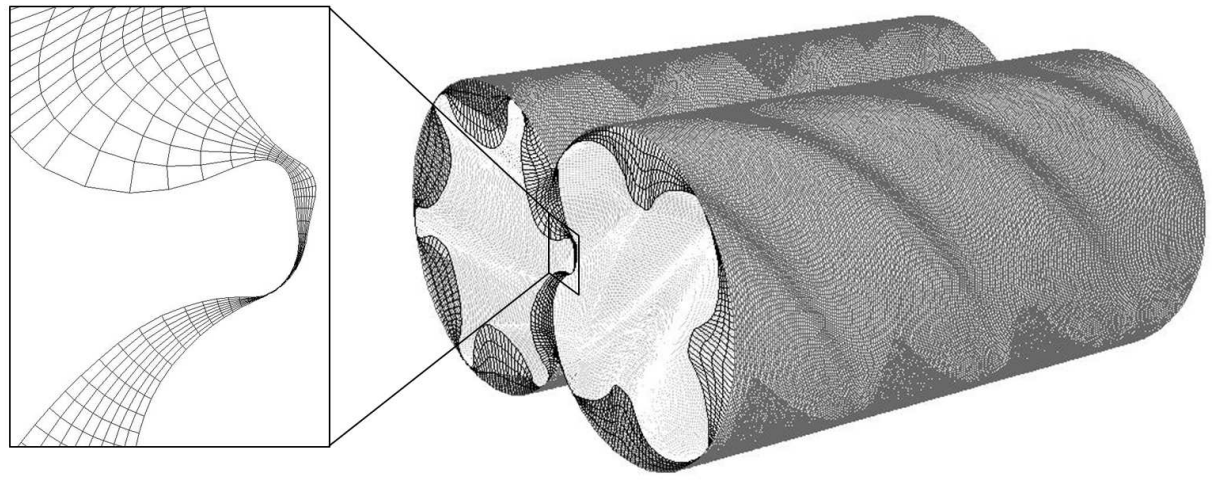

Figure 5: Mesh in the rotor domain with detail of the mesh in the gap in-between the rotors [18] 
equipotential lines. The rotor domain is further divided into two blocks, male and female, by the division line. In Fig. 4, this line is drawn from cusp to cusp and it ensures good quality of the cells in the cusp region. Furthermore, necessary refinements were done as described in [15].

These two-dimensional structured meshes are constructed in slices corresponding with different rotation of the screws before the CFD simulation. The number of slices depends on the number of time steps per cycle and the axial resolution. By stacking these two-dimensional grids in slices, a full 3D grid in the rotor domain is created (Fig. 5). The grid motion algorithm is implemented in Ansys Fluent using user-defined functions (UDFs). The connection of the grid in the stationary parts (inlet, outlet and additional ports) and the rotor domain is done through sliding interfaces.

\section{Real Gas Equation of State for R245fa}

$\mathrm{R} 245 \mathrm{fa}$, also known as 1,1,1,3,3-Pentafluoropropane, is a common refrigerant used in ORC systems [19]. It is characterized by a positive slope of the saturated vapour line in the T-s diagram which will prevent the formation of liquid droplets at the exit of the expander. The properties of R245fa are shown in Table 2

\begin{tabular}{|llc|}
\hline Property & Symbol & Value \\
\hline \hline Critical temperature & $T_{c}$ & $427.2 \mathrm{~K}$ \\
Critical pressure & $P_{c}$ & $3.64 \mathrm{MPa}$ \\
Critical density & $\rho_{c}$ & $517 \mathrm{~m}^{3} / \mathrm{kg}$ \\
Acentric factor & $\omega$ & 0.3724 \\
Molecular weight & $M$ & $134.0482 \mathrm{~g} / \mathrm{mol}$ \\
\hline
\end{tabular}

Table 2: Properties of R245fa

Before implementing the real gas effects in the CFD calculations, the difference between the ideal gas EoS, the

Aungier Redlich-Kwong (ARK) EoS and CoolProp has been evaluated. CoolProp is an open-source thermophysical property library that mirrors many of the functionalities of REFPROP and has recently been developed by Bell et al. [20, 21]. The Aungier Redlich-Kwong EoS [22] represents a modified form of the Redlich-Kwong EoS. This new correlation includes an acentric factor and the critical point compressibility factor as additional parameters to improve its accuracy. The Aungier Redlich-Kwong EoS for R245fa is defined with the following equations:

$$
P=\frac{R T}{(v-\tilde{b})}-\frac{a(T)}{v\left(v+b_{0}\right)}
$$

where:

$$
\begin{aligned}
& n=0.4986+1.1735 \omega+0.475 \omega^{2}, a(T)=a_{0}\left(\frac{T_{c}}{T}\right)^{n}, \\
& a_{0}=0.42747 \frac{R^{2} T_{c}^{2}}{\rho_{c}}, b_{0}=0.08664 \frac{R T_{c}}{P_{c}} \\
& \tilde{b}=b_{0}-c_{0}, c_{0}=\frac{R T_{c}}{P_{c}+\frac{a_{0}}{v_{c}\left(v_{c}+b_{0}\right)}}+b_{0}-v_{c}
\end{aligned}
$$

The working conditions in this research are between 1bar-7bar and 350K-400K. In Fig. 6 and Fig 7 relative deviations of the pressure for the ideal gas EoS and ARK EoS compared to CoolProp are shown. It can be seen that the maximal deviations in the working conditions for ideal gas EoS are up to 100\% comparing to the ARK EoS where they reach maximum $15 \%$. In order to indicate the change in the thermodynamic properties during the expansion process of the expander the results of the CFD calculations for the design without additional ports as presented in 


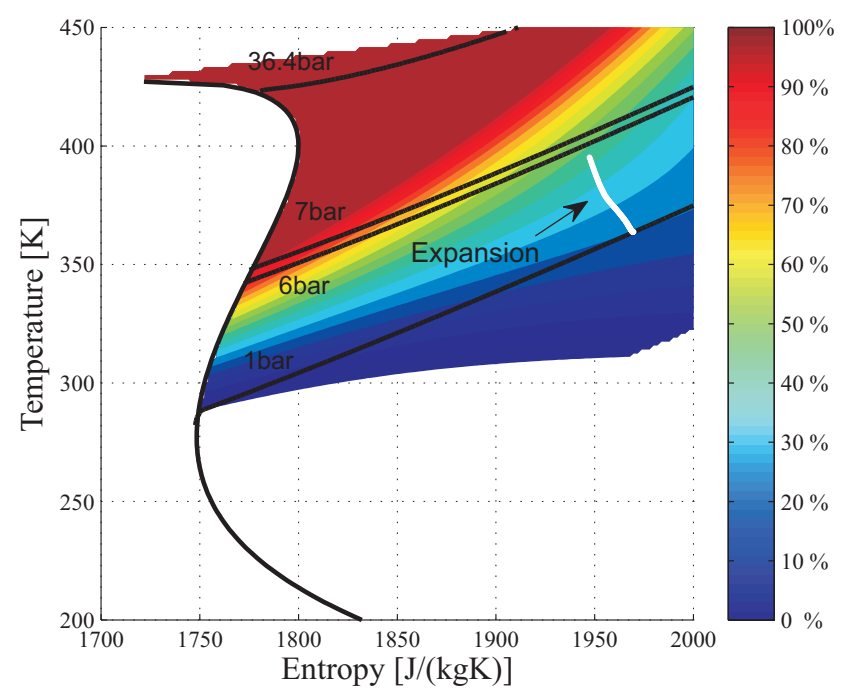

Figure 6: Pressure deviation of R245fa by using ideal gas EoS compared to CoolProp (color scale is clipped to 100\%)

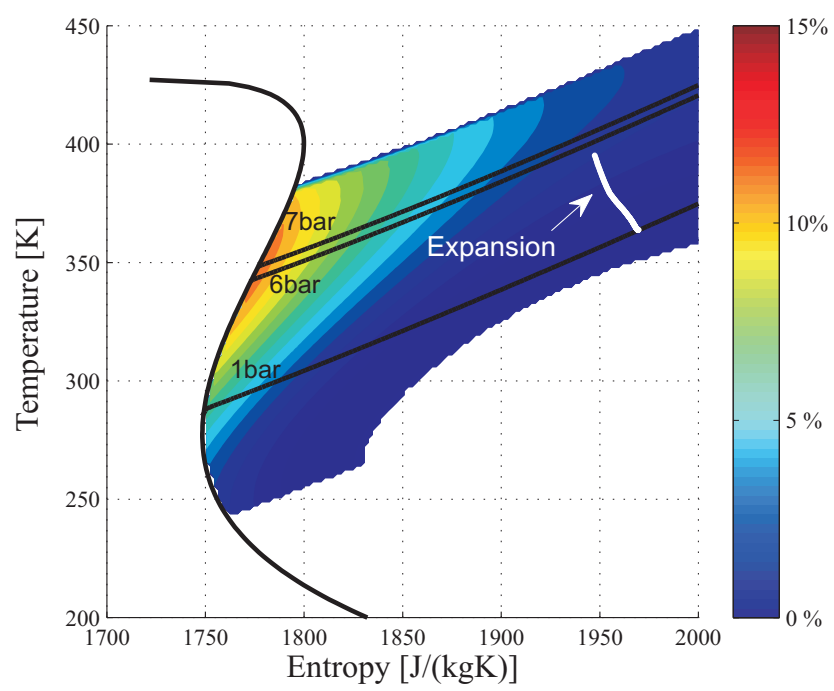

Figure 7: Pressure deviation of R245fa by using Aungier Redlich-Kwong EoS compared to the CoolProp

150 Section 7 are shown (discussion follows further). From Fig. 6 and Fig 7 it can be seen that the maximal deviation of the ARK EoS is around 3\% and for the ideal gas EoS around 50\% compared to CoolProp.

With the rotor motion and extremely small cells in the gap region, it is possible that during the first rotations of the screw expander, the properties of the working fluid fall outside the gas region. This can cause convergence problems during the start up for the ARK EoS. In that case the partial derivative of pressure at constant temperature with respect to specific volume becomes positive and this can cause convergence problems. To overcome this problem, the Aungier modified form was implemented in the CFD solver through UDFs with additional limiting functions. These limiting functions are disabled after the start-up period, when the flow reaches a periodic regime, so they have no influence on the end result. 


\section{CFD analysis} inlet/outlet pressure boundary conditions are used. In all calculations the temperature of the working fluid at the inlet
was set to $400 \mathrm{~K}$.

The pressure ratio is defined as the ratio between inlet and outlet pressures. The outlet pressure was set to $1 \mathrm{bar}$ in

\section{to 1 bar respectively.}

For the calculations, some simplifications have been made. The clearances at the end planes of the screw expander are neglected. Since this leakage loss is not included in the calculation it is expected that the filling factor will be slightly different. Also, the deformation of the rotors and the casing due to the difference in temperature of the working fluid, are not incorporated in the CFD calculations. It can be expected that closer to the inlet, clearances inside the expander will be smaller due to the deformations of the rotor with the entrance of the hot working fluid [23, 24].

Additionally, all walls are considered to be adiabatic. The cooling of the casing that happens in reality to avoid the deformation of the casing can be ignored due to the short residence time of the working fluid. Therefore, the assumption of the adiabatic walls is valid.

\section{Volumetric and isentropic efficiencies}

The volumetric efficiency of the screw expander is represented by the filling factor according to [25]. The latter is defined as the ratio between the calculated mass flow rate and the mass flow rate theoretically displaced by the expander as following:

$$
\phi_{\text {fill }}=\frac{\dot{m}_{\text {calc, fill }} v\left(T_{\text {fill }}, P_{\text {fill }}\right)}{n_{m r} z_{m r} V_{\text {fill }}}
$$

The filling factor is affected by two effects. First one is the throttling loss during the filling and the second one is leakages through the clearances in the expander. From Fig. 3 it can be seen that it is only for a short time that the surface of the inlet port is completely open (maximal inlet area) for the filling. This will cause the throttling loss. On the other hand, there are four types of leakage paths formed inside the screw expander that will affect the filling factor. These leakage flows are directed from the high pressure side towards the low pressure side providing an additional mass that will prolong the expansion and increase the filling factor. Because of the mentioned effects the filling factor of screw expanders can be greater than, lower than or equal to 1 .

In the geometry with additional ports, filling occurs during two separated moments, when the inlet port is open and when the additional ports are open. These two moments are not overlapping during the cycle. In order to investigate the influence of the addition of the working fluid through ports, the following equation is used:

$$
\phi_{\text {ports }}=\frac{\dot{m}_{\text {calc, ports }} v\left(T_{\text {ports }}, P_{\text {ports }}\right)}{n_{m r} z_{m r} V_{\text {ports }}}
$$

In the equation above it is assumed that the working fluid that is trapped inside the chamber is neither compressed nor expanded during the addition of working fluid. 
To see how much of the energy provided to the screw expander is in fact used for the useful work on the rotor surfaces, the isentropic efficiency is calculated. It is defined as the ratio between the calculated shaft power and the isentropic work:

$$
\eta_{i s}=\frac{\dot{W}_{\text {exp }, \text { calc }}}{\dot{W}_{i s}}
$$

Where:

$$
\dot{W}_{i s}=\dot{m}_{f i l l}\left(h\left(T_{\text {fill }}, P_{\text {fill }}\right)-h\left(P_{\text {dis }}, s_{\text {fill }}\right)\right)
$$

In order to calculate the isentropic power for the design with additional ports, two approaches were used. In the first approach it is assumed that the pressure in the additional ports and the inlet is the same. It means that losses through the additional ports are included in the calculation of the isentropic work. Therefore, the same equation as for the design without additional ports is used but with the addition of the mass flow rate through the ports:

$$
\dot{W}_{i s}=\left(\dot{m}_{f i l l}+\dot{m}_{i n j}\right)\left(h\left(T_{f i l l}, P_{\text {fill }}\right)-h\left(P_{\text {dis }}, s_{\text {fill }}\right)\right)
$$

If the efficiency is calculated with the pressure drop already included in the calculations, meaning that the pressure in the additional ports is not the same as the inlet pressure, the following equation should be used:

$$
\dot{W}_{i s}=\dot{m}_{\text {fill }}\left(h\left(T_{\text {fill }}, P_{\text {fill }}\right)-h\left(P_{\text {dis }}, s_{\text {fill }}\right)\right)+\dot{m}_{\text {ports }}\left(h\left(T_{\text {ports }}, P_{\text {ports }}\right)-h\left(P_{\text {dis }}, s_{\text {ports }}\right)\right)
$$

\section{Results and discussion}

\subsection{Grid and time step refinement}

The rotor domain was analysed for two levels of grid refinement as shown in Fig. 8 The number of divisions and the number of cells for both cases are presented in Table 3 Both the grid and the time step refinement study are done for the design without additional ports and for the inlet pressure of 6 bar.

\begin{tabular}{|l||c|c|c|c|c|}
\hline Case & Supplied grids & Radial divisions & $\begin{array}{c}\text { Circumf. } \\
\text { divisions }\end{array}$ & $\begin{array}{c}\text { Axial divisions } \\
\text { Cells in rotor } \\
\text { domain }\end{array}$ \\
\hline Coarse & 60 & 4 & 485 & 250 & 570000 \\
\hline Fine & $60,120,240$ & 7 & 650 & 403 & 2200380 \\
\hline
\end{tabular}

Table 3: Number of cells in the rotor domain of the twin screw expander

The influence of grid refinement on the prediction of the mass flow rate is shown in Fig. 9 The difference between the coarse and fine grid is less than $1.7 \%$ for 60 time steps per cycle (4 cycles during one rotation). This level was satisfying comparing to [14] where the change in mass flow rate is less than $3 \%$ between the two finest grids. Although in [14] divisions in radial and tangential direction are higher, stretching of the grid near the gaps (Fig. 8) used in this paper allows better leakage predictions. For the power output, similarly to the mass flow rate, the difference between the coarse and fine grid is less than $1 \%$.

Additional time step analysis was done for the finest grid. The influence of a change in time step is shown in Fig. 9. Comparing different numbers of time steps per cycle it can be seen that the maximum difference for the mass flow rate between the 60 and 240 time steps per cycle is around 3\%. For the power output, the difference between 60 and 120 time steps per cycle is around $1.6 \%$ and between 60 and 240 time steps per cycle around $3 \%$. 

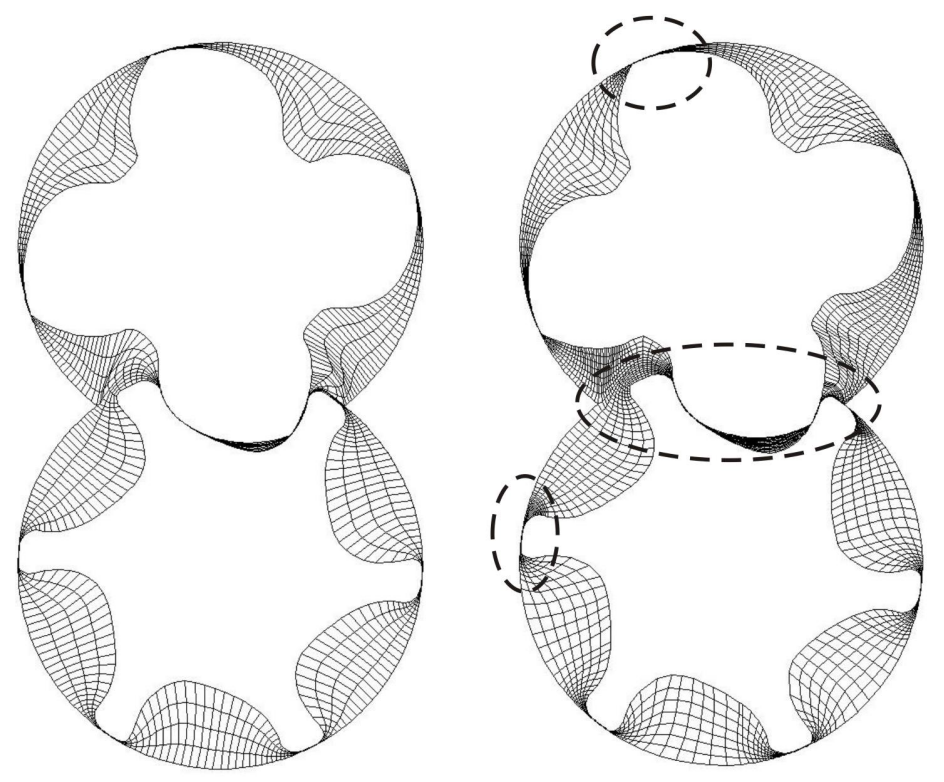

Figure 8: Grid refinement in a two-dimensional section of the rotor domain

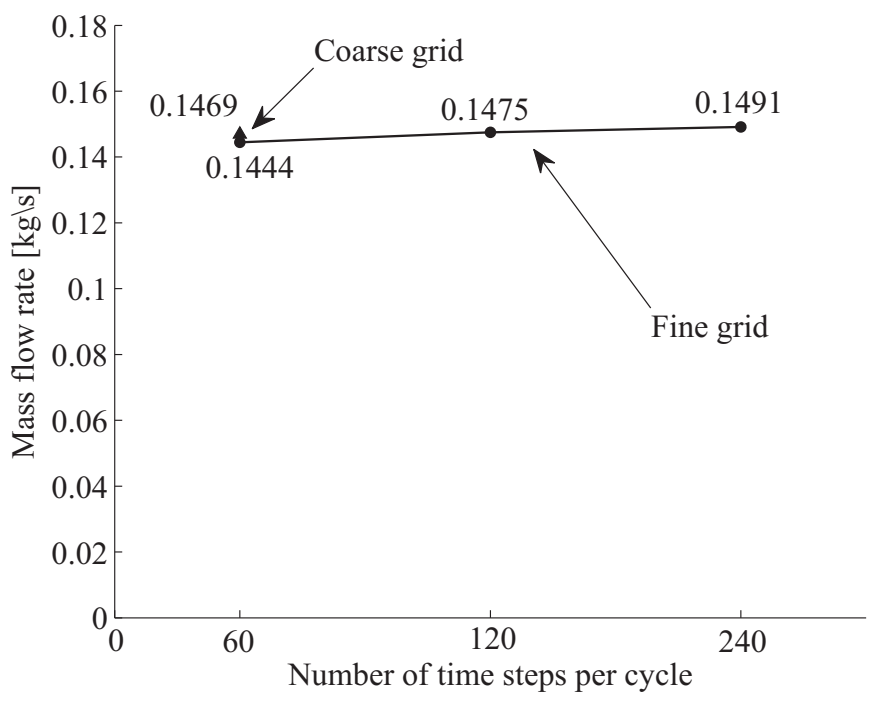

Figure 9: Mass flow rates for two levels of grid refinement and different sizes of the time step for the finest mesh

\subsection{Pressure Volume Diagram}

$\mathrm{P}-\mathrm{V}$ diagrams for inlet pressures between $p_{i n}=6 \mathrm{bar}$ and $p_{\text {in }}=2 \mathrm{bar}$ for both designs are presented in Fig. 10 and Fig. 11. Moments of closing the inlet port, opening and closing of the additional ports and opening of the outlet are depicted.

When comparing both designs, it can be seen that with working fluid entering also through the additional ports, the PV-curve changes shape which will affect the performance of the expander.

Compared to the ideal isobaric filling, a significant throttling loss is present during the filling for both designs as depicted in Fig. 12 Looking from the high pressure side, fluid starts to fill the chamber formed between the lobes of 


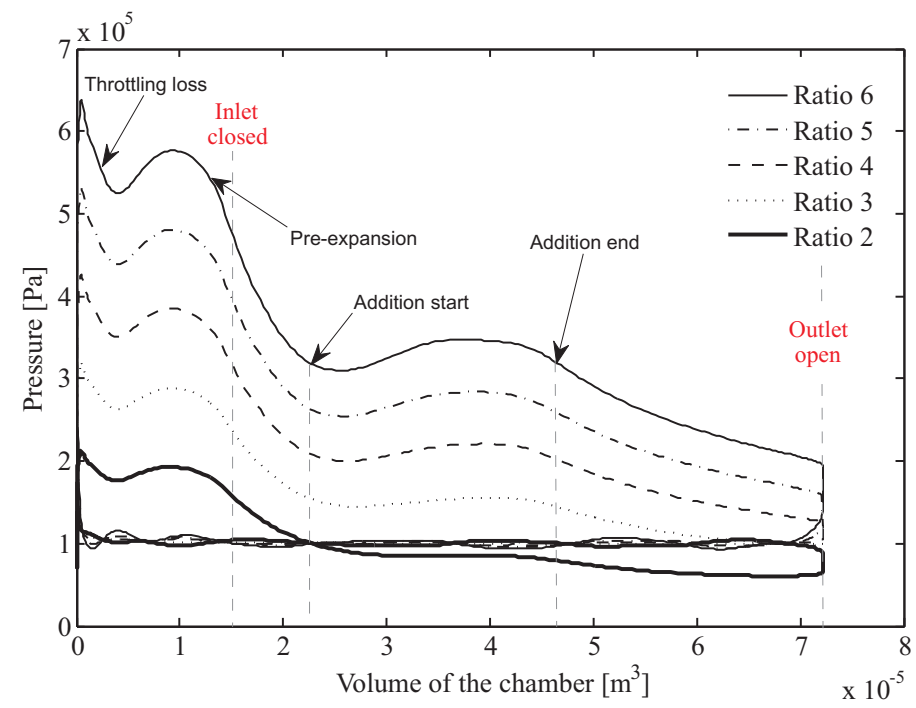

Figure 10: P-V diagram of the expansion for different pressure ratios (design with additional ports)

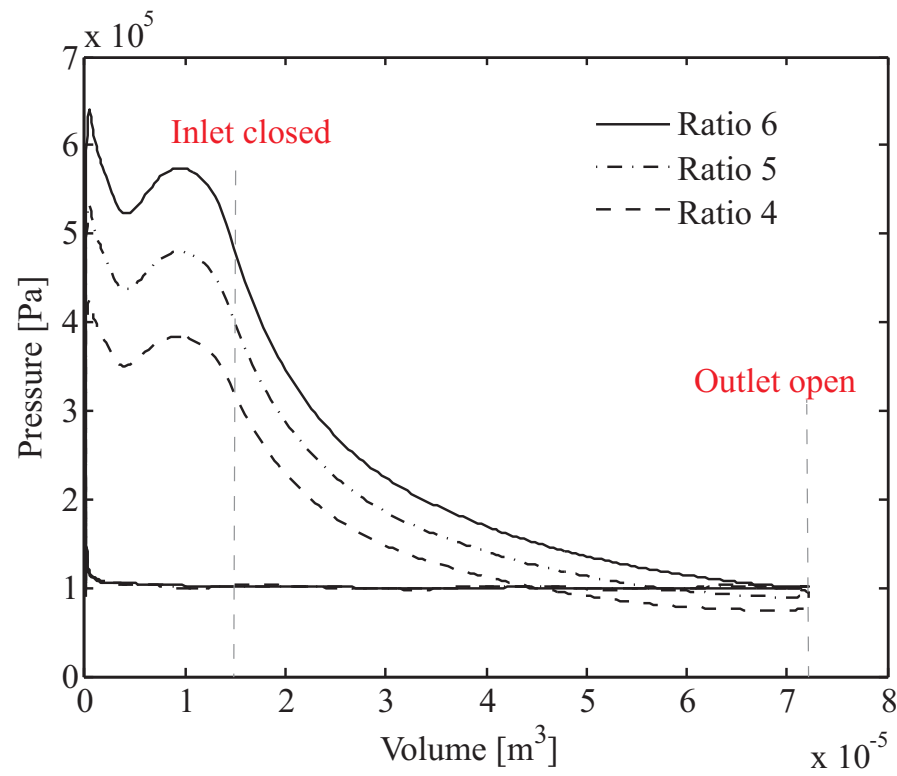

Figure 11: P-V diagram of the expansion for different pressure ratios (design without additional ports)

the rotor profiles and the casing of the expander. At the beginning, during a small fraction of time, a certain pressure rise is present because the inlet port was closed and the fluid could not enter the chamber (Fig. 12,(1)). This cause travelling wave in the inlet pipe, which even result in a higher pressure in the inlet pipe just after the opening of the inlet area (Fig. 12, top left). The expansion of the working fluid in combination with a small inlet area causes a minimum in the chamber pressure (Fig. 12,(2)). With the inlet port being more and more open, the pressure will again start to rise until it reaches its maximum with the inlet port completely open (Fig. 12,(3)). After that, the inlet starts to close and the working fluid enters further through the decreasing inlet area. Even though the inlet is closing, the volume of the chamber is still increasing. This will cause the so called pre-expansion (Fig. 12,(4)). After that the chamber is disconnected from the inlet (Fig. 12,(4)). In the next moment, a new chamber is formed and it will be connected to the inlet pipe (Fig. 12,(5)).

From the analysis above, it can be concluded that the inlet port should be designed in a such way that filling occurs 


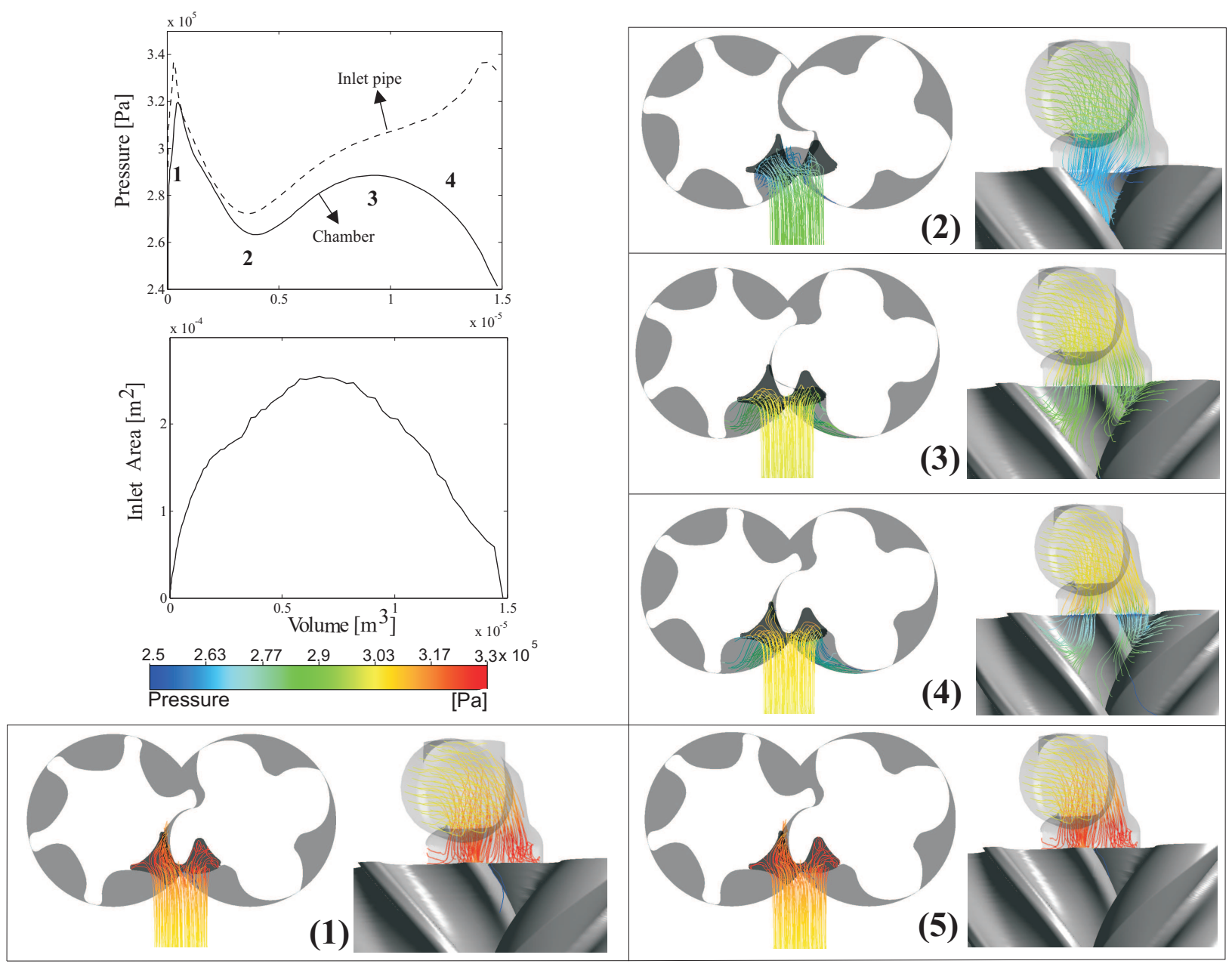

Figure 12: Analysis of the filling phase for the pressure ratio of 3. Left top: P-V curve and area change for the physical chamber (male and female) during the filling. Right and bottom: streamlines coloured by the pressure.

only during a small part of the growing phase of the volume with maximum inlet surface area available. In that case the throttling losses that occur during the filling can be minimized. Theoretically, the best moment to stop with filling would be when the pressure in the chamber is the highest. But since it happens when the volume of the chamber is still small, the mass in the chamber is not high.

At the moment the inlet port is completely closed, expansion should theoretically start, although the pre-expansion can occur already during the filling as mentioned. During the expansion of the working fluid, addition of working fluid through two ports will cause an increase in pressure in the chamber, despite its increasing volume (Fig. 10). As the chamber meets the outlet port, the fluid in the chamber is discharged. Depending on the imposed pressure ratio, over- or under-expansion can occur.

\subsection{Calculations with air and R245fa for ideal gas, ARK EoS and CoolProp}

In this section, results of calculations performed with air and R245fa are presented. Air is modelled with the ideal gas EoS and R245fa with the ideal gas EoS, the ARK EoS and CoolProp. In calculations with the ideal gas EoS, both air and R245fa are calculated with a constant $c_{p}$ of $1004 \mathrm{~J} / \mathrm{kgK}$ and $1045 \mathrm{~J} / \mathrm{kgK}$ respectively.

In Fig $13 \mathrm{P}-\mathrm{V}$ curves for all cases are presented. It is concluded that the results with air as a working fluid are not representative for a twin screw expander with R245fa and should not be further considered. Furthermore for R245fa the difference in the P-V curve can be seen between ideal gas and ARK EoS. In Table 4, the differences in mass flow 


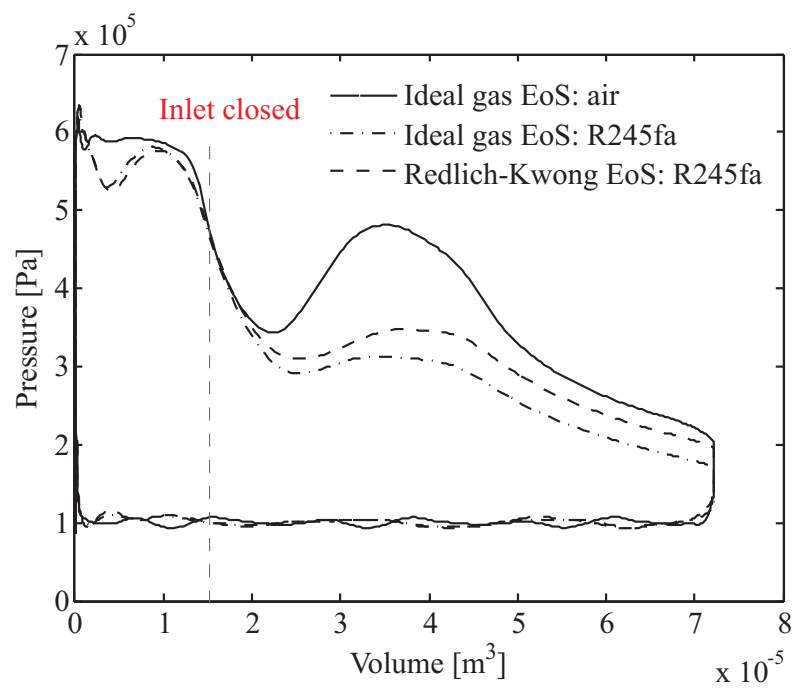

Figure 13: P-V diagram for pressure ratio 6 for the ideal gas EoS and the Aungier Redlich-Kwong EoS

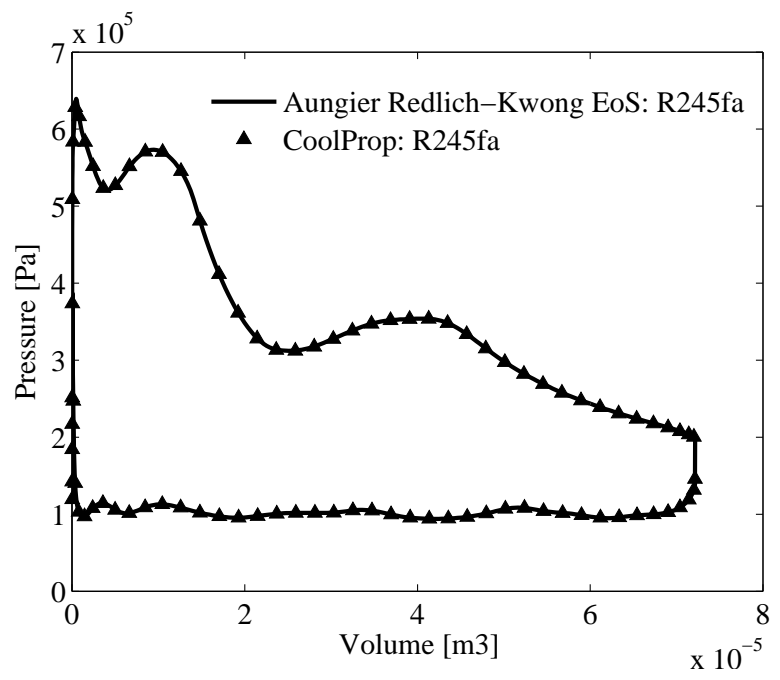

Figure 14: P-V diagram for pressure ratio 6 for the Aungier Redlich-Kwong EoS and CoolProp

rates and power output are shown for calculations with R245fa. It can be seen that the power output for R245fa with the use of ideal gas EoS is around $8 \%$ smaller than with the use of the ARK EoS.

Table 4: CFD model prediction for ideal gas and ARK EoS for R245fa

\begin{tabular}{|l||c|c|c|}
\hline & Inlet $(\mathrm{kg} / \mathrm{s})$ & Ports $(\mathrm{kg} / \mathrm{s})$ & Power $(\mathrm{kW})$ \\
\hline ideal gas: $R 245 f a$ & 0.1368 & 0.112 & 6.57 \\
\hline ARK:R245fa & 0.1462 & 0.1445 & 7.14 \\
\hline
\end{tabular}

A comparison has been made between the ARK EoS and CoolProp. P-V curves for the ARK EoS and CoolProp are on a top of each other (Fig 14). The difference in power output is less than $0.2 \%$. However it is to be expected that this difference would slightly increase with temperature and pressure being closer to the saturation line. The difference in calculation time between these two models is large: the calculation time is almost twice as large when calculating with CoolProp. 


\subsection{Performance Analysis}

The calculated power and mass flow rates for different pressure ratios and both designs are shown in Fig. 15a. It can be seen that both the mass flow rate and the power are increasing linearly with respect to pressure ratio. For the same pressure ratio, the design with additional ports has approximately two times higher mass flow rate (through the inlet and two additional ports), and approximately 1.5 times higher power. In order to exclude the influence of the mass flow rate the specific power is calculated for both designs and shown in Fig. 15b It can be seen that the power per unit mass flow rate is higher for the design without additional ports. Comparing the isentropic efficiency for both designs in Fig. 16b the design with additional ports also shows a smaller isentropic efficiency compared to the design without additional ports. The advantage however to have these additional inlet ports is that in case of the use of the expander in an ORC cycle with a variable heat source the operational power range of the expander can be largely increased since more power can be generated by opening these additional inlet ports, although the efficiency is somewhat reduced.

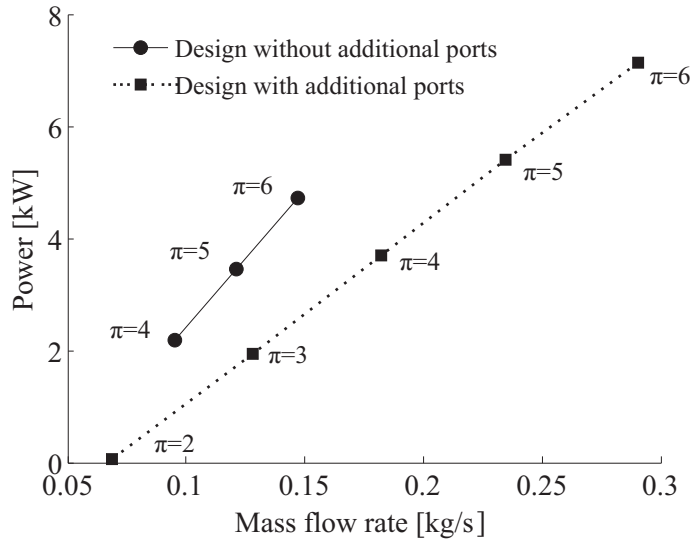

(a) Calculated power output

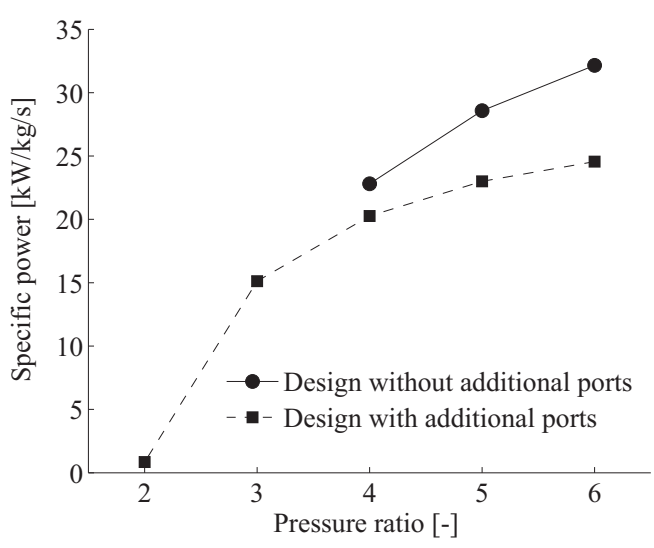

(b) Specific power

Figure 15: Calculated and specific powers for different pressure ratios and both designs of twin screw expander

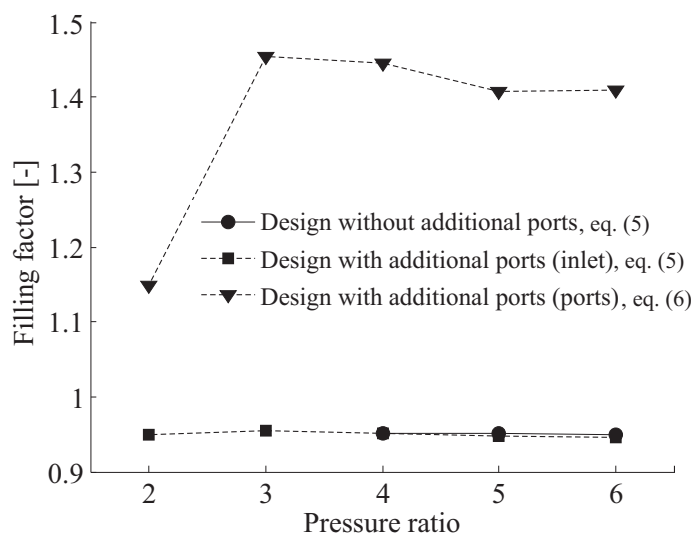

(a) Filling factor

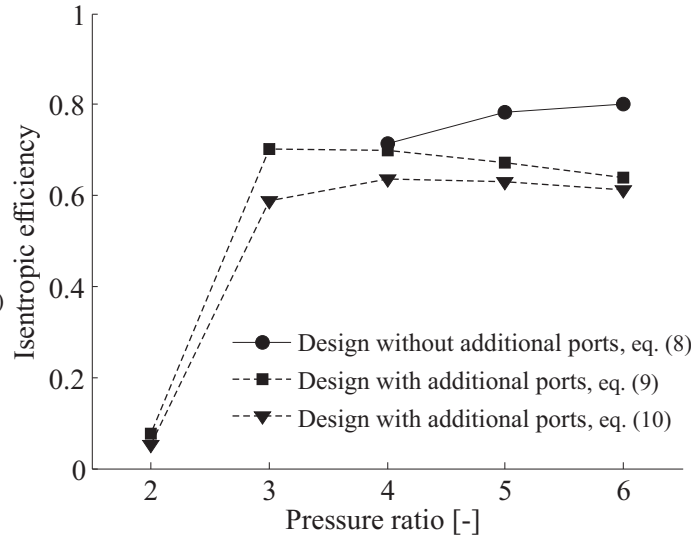

(b) Isentropic efficiency

Figure 16: Fiiling factor and isentropic efficiency versus pressure ratio for both designs

Since the addition of working fluid through the additional ports is not overlapping with the filling, filling factors calculated with Equation (5) for both designs and with the same operating conditions are almost the same (Fig. 16a). 


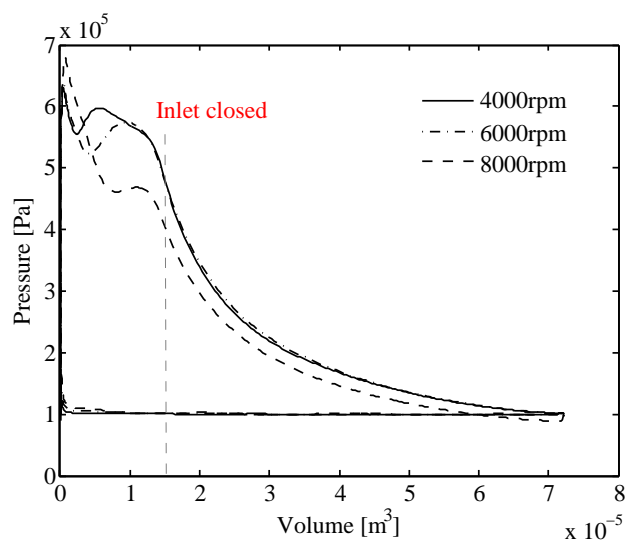

(a) Design without additional ports

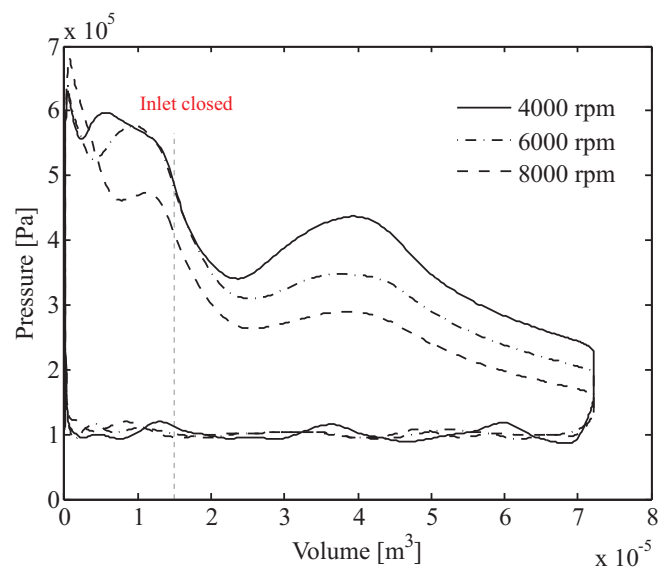

(b) Design with additional ports

Figure 17: P-V diagrams of the expansion for different rotational speeds and pressure ratio 6

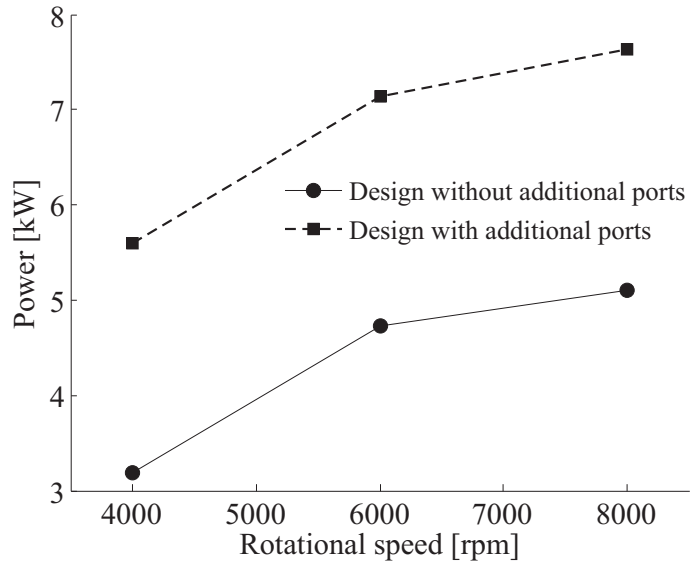

(a) Power

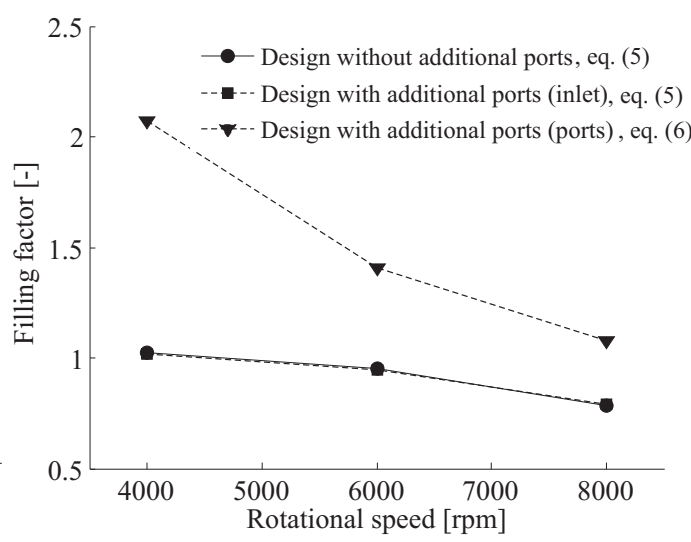

(b) Filling factor

Figure 18: Calculated powers and filling factors for different rotational speeds and pressure ratio 6 (both designs)

The only difference is the leakage mass flow rate through the clearances with the adjacent chamber. The adjacent chamber is connected to the additional ports which will result in higher pressure and therefore different leakage mass ports is higher than 1 .

\subsection{Speed change analysis}

The performance of the expander was also examined with variations in speed. In Fig. 18a it is shown that despite the expectation of a linear rise of the power with the rotational speed, the power for 8000rpm increases less than linearly. This can be explained with the P-V diagram in Fig. 17a and Fig. 17b Due to the shorter duration of the filling period with the rise in the rotational speed, it can be seen that the throttling loss increases. Hence, the power output increases less than linearly with the increase in the rotational speed. This can be proved by looking at the filling factor in Fig. 18b which is decreasing with the increase in rotational speed. 

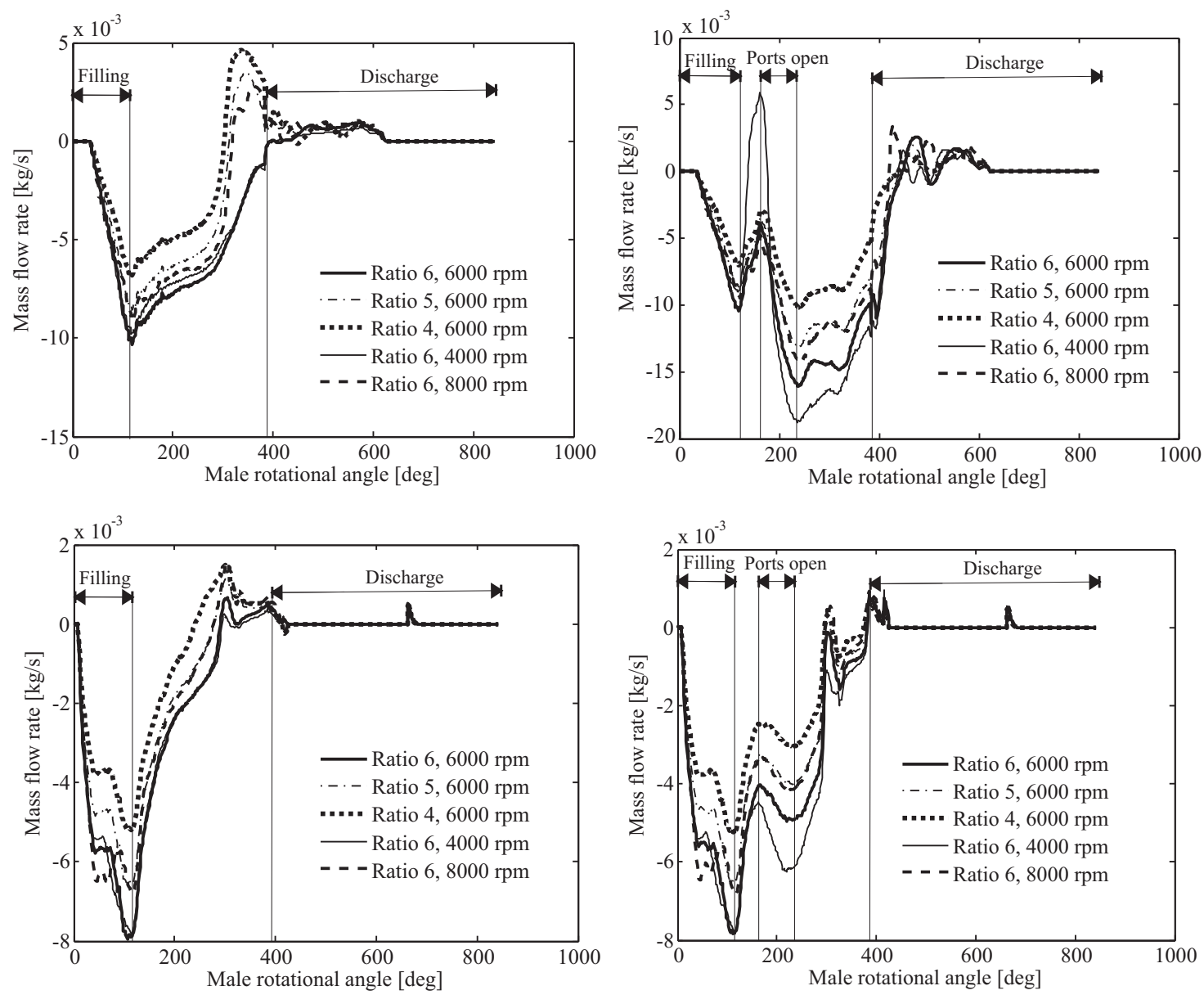

Figure 19: Leakage flows through tip and sealing clearance gaps (left:design without additional ports; right: design with additional ports; top:male tip leakages; bottom:sealing leakages)

\subsection{Leakage flows through the design related clearances in screw expander}

Leakage flows have been evaluated for the two designs with change in pressure ratio and rotational speed. In Fig. 19 the male tip and the sealing leakage flows are presented with respect to the male rotation angle. A negative value in the figure corresponds to fluid that is leaving the working chamber. Only the leading tip for the male side of the working chamber is presented since the curve for the trailing tip is in fact the one for the leading tip shifted by $\theta=90^{\circ}$ and with opposite sign.

For both designs, with increase in pressure ratio leakage flows will increase since the total mass flow rate changes linearly with respect to pressure ratio (Fig. 19]. However, with change in speed, throttling losses at the inlet which increase with rotational speed will influence the pressure in the chamber (Fig. 17a and Fig. 17b). From Fig. 19.bottom), it can be seen that sealing leakage flows during the first phase of the filling will increase with rotational speed. However, at the end of the filling and during the expansion this is not the case. Instead of high leakage flows for a rotational speed of $8000 \mathrm{rpm}$, leakage flows are higher for rotational speeds of $4000 \mathrm{rpm}$ and $6000 \mathrm{rpm}$. The reason for this are the high pressures in the chamber (Fig. 17a and Fig. 17b) for these rotational speeds at these moments. In the same way, high tip leakage flows (Fig. 19, top) for low rotational speeds can be explained. Therefore, it can be concluded that the influence of leakage flows on the performance of the expander will be greater at lower speeds and high pressure ratios. With addition of working fluid through additional ports, leakage flows are increasing (Fig. 19 right) due to higher pressure in the chamber. 


\section{Conclusion}

Transient 3D CFD calculations of the twin screw expander have been successfully performed. The same approach developed by the authors for the screw compressor was used for calculations of the screw expander. CFD calculations were performed for two working fluids, air and R245fa by using appropriate equations of state, ideal gas EoS and Aungier Redlich-Kwong EoS respectively. It was shown that with the use of the ideal gas EoS for R245fa, the power output is $8 \%$ smaller than with the use of the ARK EoS. The difference in power output between ARK EoS and CoolProp is negligible for operating conditions of interest.

For the performance analysis, calculations with different pressure ratios and different operating speeds have been performed for two different designs of the twin screw expander. It is concluded that the mass flow rate increases with both higher pressure ratio and higher rotational speed. With the use of additional inlet ports the operational range of the power output of the expander can significantly be increased. However during operation with the use of the additional inlet ports the specific power and isentropic efficiency is somewhat smaller. The mass flow rates through the tip and sealing clearances have been analysed with the respect to male rotational angle. It is shown that the influence of the leakage flows is greater at lower speeds and higher pressure ratio. The study also shows that the main design change should be done at the inlet port in order to minimise throttling losses.

The procedure developed in this paper will be used further to optimise the performance of screw expanders for different applications with changes in operating conditions and design.

\section{Acknowledgement}

This study is part of the ORCNext project with financial support of IWT Flanders. This work was carried out using the STEVIN Supercomputer Infrastructure at Ghent University, funded by Ghent University, the Flemish Supercomputer Center (VSC), the Hercules Foundation and the Flemish Government (department EWI).

\section{References}

[1] V. Lemort, L. Guillaume, A. Legros, S. Declaye, S. Quoilin, A comparison of piston, screw and scroll expanders for small scale Rankine cycle systems, Proceedings of the 3rd International Conference on Microgeneration and Related Technologies.

2] S. Quoilin, V. Lemort, J. Lebrun, Experimental study and modelling of an Organic Rankine Cycle using scroll expander, Applied Thermal Engineering 87 (2010) 1260-1268.

[3] D. Margolis, Analytical Modeling of Helical Screw Turbines for Performance Prediction, ASME J. Engineering for Power 100 (1978) $482-$ 487.

[4] H. Taniguchi, K. Kudo, W. H. Giedt, I. Park, S. Kumazawa, Analytical and experimental investigation of two-phase flow screw expanders for power generation, Trans ASME, J. Engng for Gas Turbines and Power 110(4) (1988) 628-635.

[5] D. Elliott, Theory and Tests of Two-Phase Turbines, Jet Propulsion Laboratory Publication (1982) 81-105.

[6] I. Smith, Development of the Trilateral Flash Cycle System Part 1: Fundamental considerations, Proceedings of Institution of Mechanical Engineers 207(A3) (1993) 179-194.

[7] I. Smith, N. Stosic, C. Aldis, Development of the Trilateral Flash Cycle System Part 3: The design of high-efficiency two-phase screw expanders, Proceedings of Institution of Mechanical Engineers 210(A2) (1996) 75-92.

[8] I. Smith, N. Stosic, A. Kovacevic, Screw expanders increase output and decrease the cost of geothermal binary power plant systems, Geothermal Resource Council Transactions 29 (2005) 787-794.

[9] Z. Wang, Y. Zhang, Y. Sun, L. Wei, Numerical simulation and experimental study on the performance of screw expander, ASHRAE Transactions 116,part 2 (2010) 218-225.

345 [10] N. Stosic, I. Smith, A. Kovacevic, Optimisation of screw compressors, Applied Thermal Engineering 23 (2003) 1177-1195.

[11] A. Kovacevic, N. Stosic, I. Smith, Development of CAD-CFD interface for screw compressor design, International Conference on Compressors and their Systems IMechE Proceedings (1999) 757-767, Paper C542-075.

[12] A. Kovacevic, S. Rane, 3D CFD analysis of a twin screw expander, 8th International Conference on Compressors and their Systems (2013) 417-429.

[13] J. Vande Voorde, J. Vierendeels, E. Dick, Development of a Laplacian-based mesh generator for ALE calculations in rotary volumetric pumps and compressors, Computer Methods in Applied Mechanics and Engineering 193 (39-41) (2004) 4401-4415.

[14] S. Rane, A. Kovacevic, N. Stosic, M. Kethidi, Grid deformation strategies for CFD analysis of screw compressors, Int J Refrig 36(7) (2013) 1883-1893.

[15] J. Vande Voorde, J. Vierendeels, E. Dick, ALE Calculations of Flow Through Rotary Positive Displacement Machines, In Proc. of the ASME Fluids Engineering Divison Summer Meeting and Exhibition, FEDSM2005-77353, ISBN 0-7918-3760-2,Houston, USA.

[16] J. M. Lujan, J. Serrano, V. Dolz, J. Snchez, Model of the expansion process for R245fa in an Organic Rankine Cycle (ORC), Applied Thermal Engineering 40 (2012) 248-257. 
[17] I. Smith, N. Stosic, A. Kovacevic, Expander lubrication in vapour power systems, United States Patent Application Publication Pub. No.:US 2009/0188253 A1.

[18] I. Papes, J. Degroote, E. Dick, Analysis of a Twin Screw Expander for ORC Systems using Computational Fluid Dynamics with a Real Gas Model, Proceedings of the 22nd International Compressor Engineering Conference at Purdue.

[19] S. Quoilin, S. Declaye, B. F. Tchanche, V. Lemort, Thermo-economic optimization of waste heat recovery Organic Rankine Cycles, Applied Thermal Engineering 31 (2011) 2885-2893.

[20] I. H. Bell, J. Wronski, S. Quoilin, V. Lemort, Pure and Pseudo-pure Fluid Thermophysical Property Evaluation and the Open-Source Thermophysical Property Library Coolprop, Ind. Eng. Chem. Res. 53(6) (2014) 2498-2508.

[21] I. H. Bell, S. Quoilin, J. Wronski, V. Lemort, CoolProp: An open-source reference-quality thermophysical property library, ASME ORC 2nd International Seminar on ORC Power Systems.

[22] R. H. Aungier, A fast, accurate real gas equation of state for fluid dynamic analysis applications, Journal of Fluids Engineering 117 (1995) 277-281.

370 [23] N. Stosic, On heat transfer in screw compressors, International Journal of Heat and Fluid Flow 51 (2015) $285-297$.

[24] A. Kovacevic, N. Stosic, I. Smith, A Numerical Study of Fluid-Solid Interaction in Screw Compressors, International Journal of Computer Applications in Technology (IJCAT) 21, No.4. (2004) 148-158.

[25] V. Lemort, S. Quoilin, C. Cuevas, J. Lebrun, Testing and modeling a scroll expander integrated into an organic rankine cycle, Applied Thermal Engineering 29 (2009) 3094-3102. 